\title{
Predictive value of preoperative tissue Doppler echocardiographic analysis for postoperative atrial fibrillation after pulmonary resection for lung cancer
}

Takashi Nojiri, MD, ${ }^{\mathrm{a}}$ Hajime Maeda, MD, PhD, ${ }^{\mathrm{a}}$ Yukiyasu Takeuchi, MD, PhD, ${ }^{\mathrm{a}}$ Yasunobu Funakoshi, MD, $\mathrm{PhD},{ }^{\mathrm{a}}$ Ryoji Maekura, MD, PhD, ${ }^{\mathrm{b}}$ Kazuhiro Yamamoto, $\mathrm{MD}, \mathrm{PhD},{ }^{\mathrm{c}}$ and Meinoshin Okumura, MD, $\mathrm{PhD}^{\mathrm{d}}$

Objective: The objective of the present study was to evaluate the utility of tissue Doppler imaging for predicting the development of postoperative atrial fibrillation.

Methods: In this prospective observational study, we evaluated 126 patients with lung cancer who underwent a lobectomy during the 18-month period from August 2007 to January 2009. Preoperative evaluations for all patients included tissue Doppler imaging in addition to conventional echocardiographic analysis. The study end point was the development of postoperative atrial fibrillation.

Results: Postoperative atrial fibrillation was identified in 29 (23\%) patients, in whom significantly higher early transmitral velocity/tissue Doppler mitral annular early diastolic velocity values were noted compared with those seen in patients without atrial fibrillation $(9.76 \pm 2.3$ vs $7.14 \pm 1.7, P<.0001)$. The area under the receiver operating characteristic curve for early transmitral velocity/tissue Doppler mitral annular early diastolic velocity to predict postoperative atrial fibrillation after pulmonary resection for lung cancer was 0.83 ( $95 \%$ confidence interval, $0.74-0.92 ; P<.001)$. An early transmitral velocity/tissue Doppler mitral annular early diastolic velocity value of greater than 8 had a sensitivity of $90 \%$ and a specificity of $73 \%$ for predicting postoperative atrial fibrillation.

Conclusions: Postoperative atrial fibrillation after pulmonary resection might be associated with left ventricular diastolic dysfunction before surgical intervention revealed by using tissue Doppler imaging. Additional studies to establish the significance of tissue Doppler imaging as a tool to predict postoperative atrial fibrillation could contribute to improvements in lung cancer treatments. (J Thorac Cardiovasc Surg 2010;140:764-8)

Atrial fibrillation (AF) is the most common cardiac arrhythmia during the early postoperative period of pulmonary resection. ${ }^{1-4}$ Although AF after pulmonary resection is transient in most cases, it sometimes results in a serious outcome, including thromboembolic events and hemodynamic deterioration, which finally leads to increased mortality. ${ }^{5,6}$ Therefore it is desirable to identify patients with a high risk for AF and prevent the condition with the use of targeted pharmacologic strategies. Older age,,${ }^{1,2}$ male sex, ${ }^{2}$ extended resection, ${ }^{2,3}$ induction therapy, ${ }^{3}$ chronic obstructive pulmonary disease (COPD) ${ }^{4}$ and mediastinal lymph node dissection ${ }^{1}$ have been reported as risk factors for postoperative

From the Departments of General Thoracic Surgery ${ }^{\mathrm{a}}$ and Cardiology, ${ }^{\mathrm{b}}$ Toneyama National Hospital, Toyonaka-City, Osaka, Japan; and the Departments of Cardiolo$\mathrm{gy}^{\mathrm{c}}$ and General Thoracic Surgery, ${ }^{\mathrm{d}}$ Osaka University Graduate School of Medicine, Suita-City, Osaka, Japan.

Disclosures: None.

Received for publication Sept 28, 2009; revisions received Nov 4, 2009; accepted for publication Nov 18, 2009; available ahead of print Aug 9, 2010.

Address for reprints: Takashi Nojiri, MD, Department of General Thoracic Surgery, Toneyama National Hospital, Toneyama 5-1-1, Toyonaka City 560-8552, Osaka,

Japan (E-mail: nojirit@thoracic.med.osaka-u.ac.jp).

$0022-5223 / \$ 36.00$

Copyright (c) 2010 by The American Association for Thoracic Surgery doi: $10.1016 /$ j.jtcvs.2009.11.073
AF after the procedure. However, conventional methods provide only a limited ability to predict the development of postoperative $\mathrm{AF}$, and thus it is important to elucidate more specific and sensitive markers.

Because left ventricular (LV) diastolic dysfunction has been reported to be a risk factor for $\mathrm{AF}^{7,8}$ we speculated that LV diastolic dysfunction before surgical intervention might be associated with the development of postoperative $\mathrm{AF}$ after a pulmonary resection procedure.

Conventional echocardiographic assessment of LV diastolic function has been dependent on the evaluation of the pulsed-wave Doppler flow-velocity waveform recorded with the sample volume positioned at the mitral valve leaflet tips. The mitral inflow in subjects with sinus rhythm represents flow-velocity curves at early diastolic filling and atrial contraction, and a ratio of peak early diastolic mitral flow velocity (E) to peak mitral flow velocity at atrial contraction (A), the E/A ratio, has been used as an index for diastolic function. The E/A ratio should decrease with the development of diastolic dysfunction; however, it increases with an increase in LV diastolic pressure caused by progressive diastolic dysfunction. This phenomenon is termed pseudonormalization. ${ }^{9}$ In addition, the E/A ratio does not reflect diastolic dysfunction in patients with normal LV ejection 


$$
\begin{aligned}
& \text { Abbreviations and Acronyms } \\
& \begin{aligned}
\mathrm{AF}= & \text { atrial fibrillation } \\
\mathrm{COPD}= & \text { chronic obstructive pulmonary disease } \\
\mathrm{E} / \mathrm{A}= & \text { peak early diastolic mitral flow velocity } \\
& \text { to peak mitral flow velocity at atrial } \\
& \text { contraction } \\
\mathrm{E} / \mathrm{Ea}= & \text { early transmitral velocity/tissue Doppler } \\
& \text { mitral annular early diastolic velocity } \\
\mathrm{FEV}_{1}= & \text { forced expiratory volume in } 1 \text { second } \\
\mathrm{FVC}= & \text { forced vital capacity } \\
\mathrm{LV}= & \text { left ventricular } \\
\mathrm{RV}= & \text { right ventricular } \\
\mathrm{TDI}= & \text { tissue Doppler imaging }
\end{aligned}
\end{aligned}
$$

fraction. ${ }^{10}$ Thus the reliability of the mitral inflow in the detection of diastolic dysfunction is insufficient. Tissue Doppler imaging (TDI) is a noninvasive imaging modality that directly interrogates myocardial velocity with high temporal and spatial resolution. The TDI recording of the mitral annular movement during diastole represents velocity curves at early diastole and atrial contraction. In the past decade, several studies have demonstrated that a ratio of early transmitral velocity (E)/tissue Doppler mitral annular early diastolic velocity (Ea), the $\mathrm{E} / \mathrm{Ea}$ ratio (the normal value of $\mathrm{E} / \mathrm{Ea}$ is $\leq 8$ ), increases with the increase in LV diastolic pressure caused by diastolic dysfunction independently of LV ejection fraction. ${ }^{11-13}$ Based on these previous studies, the $\mathrm{E} / \mathrm{Ea}$ ratio is proposed as a first-line diagnostic index for heart failure with normal LV ejection fraction and diastolic dysfunction in the consensus statement published by the Heart Failure and Echocardiography Associations of the European Society of Cardiology. ${ }^{14}$

We have hypothesized that the presence of LV diastolic dysfunction is a risk for the development of AF after pulmonary resection and that the $\mathrm{E} / \mathrm{Ea}$ ratio is a useful predictive index. The objective of the present study was to evaluate the utility of TDI in patients undergoing pulmonary resection for lung cancer for predicting the development of postoperative AF.

\section{MATERIALS AND METHODS Study Population}

After approval by the appropriate institutional review board and waiver of informed consent, we prospectively evaluated 150 consecutive patients who underwent elective pulmonary resection procedures for non-small cell lung cancer at Toneyama National Hospital from August 2007 to January 2009. Exclusion criteria were rhythm other than sinus, dysthyroidism, renal failure requiring hemodialysis, current use of antiarrhythmic drugs, repeated pulmonary resection, moderate or severe valvular heart disease, and recent angina pectoris or myocardial infarction $(<1$ month). Also excluded were patients who underwent a lesser resection (wedge resection or segmentectomy) or a more extensive operation (bilobectomy, pneumonectomy, chest wall resection, or major vascular resection). Finally, 126 patients ( 84 male and 42 female patients; mean age, $66 \pm 9$ years) who underwent a lobectomy were selected for the present study.

All patients received preoperative epidural anesthesia for pain management, which usually remained in place for 2 to 4 days or until the chest drainage tubes were removed, after which they were switched to oral analgesia. Other postoperative management methods included early ambulation and low-flow nasal oxygen supplementation, as necessary.

Preoperative evaluations included a detailed history, physical examination, blood gas analysis, 12-lead electrocardiogram, spirometry, and TDI in addition to conventional transthoracic echocardiographic analysis. The study end point was the development of postoperative AF.

\section{Pulmonary Functional Examinations}

A spirometric test was performed before surgical intervention by using an Autospirometer System 9 (Minato Medical Science, Osaka, Japan), and vital capacity and percentage of forced vital capacity expired in $1 \mathrm{sec}-$ ond (forced expiratory volume in 1 second $\left[\mathrm{FEV}_{1}\right] /$ forced vital capacity $[\mathrm{FVC}]$ ratio) were calculated. Predicted postoperative pulmonary function was calculated by using a previously reported formula. ${ }^{15}$

\section{Echocardiographic Examinations}

Two-dimensional measurements were obtained based on the recommendations of the American Society of Echocardiography by using an ultrasonic device (SONOS 7500; Philips, Andover, Mass). Images were obtained from parasternal views and an apical 4-chamber view. The patient was placed in a left lateral decubitus position for the parasternal views and the supine position for the apical 4-chamber view. The results were analyzed by an echocardiologist blinded to all clinical, hemodynamic, and laboratory findings. LV end-systolic and end-diastolic diameters were measured with M-mode echocardiographic analysis from the left parasternal short- and long-axis views. LV mass was calculated by using the Devereux formula ${ }^{16}$ and was indexed to body surface area. LV ejection fraction was determined by using the Teicholz formula. Systolic pulmonary artery pressure was predicted from tricuspid regurgitation by using the method of Currie and coworkers. ${ }^{17}$ Pulsed Doppler transmitral flows were obtained from the apical 4-chamber view. Doppler velocity curves were recorded at $100 \mathrm{~mm} / \mathrm{s}$. Mitral inflow measurements included E, A, E/A ratio, and acceleration and deceleration time of early diastolic mitral flow velocity. Ea at the septal annular site was obtained by using TDI.

\section{Postoperative AF}

In the 3-day period after surgical intervention, continuous electrocardiographic monitoring was done for all patients to detect postoperative $\mathrm{AF}$, with additional electrocardiographic examinations performed when an irregular pulse was recognized by a physician or the nursing staff or when the patient complained of palpitations. AF was defined by an irregular rhythm with absent $\mathrm{P}$ waves confirmed by means of 12-lead electrocardiographic analysis.

\section{Statistical Analysis}

Data are reported as the means \pm standard deviations or as proportions. All data were analyzed with SPSS version 11.0 software (SPSS, Inc, Chicago, Ill). The comparison of all parameters was analyzed by using 1-way analysis of variance. Comparisons of 2 groups were made with the Mann-Whitney test, and $\chi^{2}$ testing was used for categorical variables. Logistic regression analyses were used to explore risk factors for postoperative AF. Receiver operating characteristic curves were constructed to determine optimal sensitivity and specificity.

\section{RESULTS}

The clinical and surgical characteristics of patients with and without postoperative AF are summarized in Table 1. 
TABLE 1. Patients' characteristics*

\begin{tabular}{|c|c|c|c|}
\hline Variables & $\begin{array}{l}\text { Without AF } \\
\quad(\mathbf{n}=97)\end{array}$ & $\begin{array}{l}\text { With AF } \\
(n=29)\end{array}$ & $P$ value \\
\hline Age (y) & $65 \pm 9$ & $71 \pm 8$ & .002 \\
\hline Male & $67(69)$ & $17(59)$ & .48 \\
\hline Body mass index $\left(\mathrm{kg} / \mathrm{m}^{2}\right)$ & $22.4 \pm 2.5$ & $22.2 \pm 3.0$ & .78 \\
\hline Hypertension & $40(41)$ & $16(55)$ & .09 \\
\hline Hypercholesterolemia & $27(28)$ & $8(28)$ & .98 \\
\hline Diabetes mellitus & $16(17)$ & $6(21)$ & .61 \\
\hline Ischemic heart disease & $2(2)$ & $3(10)$ & .08 \\
\hline VATS procedure & $63(65)$ & $14(48)$ & .11 \\
\hline Operating time (min) & $273 \pm 73$ & $253 \pm 61$ & .19 \\
\hline Blood loss (mL) & $118 \pm 150$ & $148 \pm 185$ & .38 \\
\hline $\begin{array}{c}\text { Mediastinal lymph } \\
\text { node dissection }\end{array}$ & $84(87)$ & $23(80)$ & .22 \\
\hline \multicolumn{4}{|l|}{ Lung cancer staging } \\
\hline IA, IB & $74(76)$ & $19(66)$ & .25 \\
\hline IIA, IIB & $11(11)$ & $6(21)$ & .20 \\
\hline IIIA, IIIB, IV & $12(12)$ & $4(14)$ & .84 \\
\hline
\end{tabular}

$A F$, Atrial fibrillation; VATS, video-assisted thoracic surgery. *Values are shown as numbers (percentages) or means \pm standard deviations, unless otherwise indicated.

Postoperative AF was identified in 29 (23\%) of the 126 pulmonary resection cases analyzed. Of 29 patients with postoperative $\mathrm{AF}, 4$ had transient $\mathrm{AF}$, and 25 required class II or III antiarrhythmic drugs. Sinus rhythm was restored in all patients. Operative mortality occurred in $1(1 \%)$ patient, who died of acute heart failure caused by prolonged sepsis after 14 days.

Patients with postoperative AF were significantly older than those without AF. In contrast, there were no statistical differences between patients with and without postoperative AF with respect to sex, body mass index, comorbidity, videoassisted thoracic surgery procedure, operating time, intraoperative blood loss, mediastinal lymph node dissection, or pathologic stage. In a comparison of the results of pulmonary function parameters between the 2 groups, patients with

TABLE 2. Preoperative pulmonary function variables*

\begin{tabular}{lccc}
\hline \multicolumn{1}{c}{ Variables } & $\begin{array}{c}\text { Without } \mathbf{A F} \\
(\mathbf{n}=\mathbf{9 7})\end{array}$ & $\begin{array}{c}\text { With } \mathbf{A F} \\
(\mathbf{n = 2 9 )}\end{array}$ & $\boldsymbol{P}$ value \\
\hline VC (\% predicted) & $109 \pm 16$ & $105 \pm 16$ & .17 \\
FEV $_{1}$ (\% predicted) & $92.6 \pm 16$ & $88.1 \pm 20$ & .15 \\
FEV $_{1}$ /FVC ratio (\%) & $76.7 \pm 8.5$ & $72.2 \pm 11$ & .03 \\
DLco (\% predicted) & $97.2 \pm 22$ & $92.5 \pm 27$ & .34 \\
RV/TLC & $37.8 \pm 6.8$ & $40.4 \pm 7.8$ & .09 \\
ppo VC (\%) & $86.9 \pm 15$ & $80.9 \pm 15$ & .07 \\
ppo FEV $(\%)$ & $74.1 \pm 14$ & $67.0 \pm 17$ & .04 \\
ppo DLco (\%) & $76.7 \pm 19$ & $70.7 \pm 24$ & .19 \\
pH & $7.41 \pm 0.02$ & $7.41 \pm 0.02$ & .54 \\
$\mathrm{PaO}_{2}(\mathrm{~mm} \mathrm{Hg})$ & $87.3 \pm 11$ & $86.0 \pm 10$ & .58 \\
$\mathrm{PaCO}_{2}(\mathrm{~mm} \mathrm{Hg})$ & $40.3 \pm 3.5$ & $39.9 \pm 3.8$ & .56 \\
\hline $\mathrm{AF}_{\mathrm{A}} \mathrm{Am}$ &
\end{tabular}

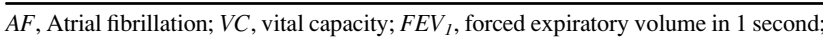
$F V C$, forced vital capacity; $D L C o$, carbon monoxide diffusing capacity; $R V / T L C$, ratio of residual volume to total lung capacity; ppo, predicted postoperative; $\mathrm{PaCO}_{2}$, carbon dioxide blood partial pressure; $\mathrm{PaO}_{2}$, arterial oxygen blood partial pressure. *Values are shown as means \pm standard deviations.

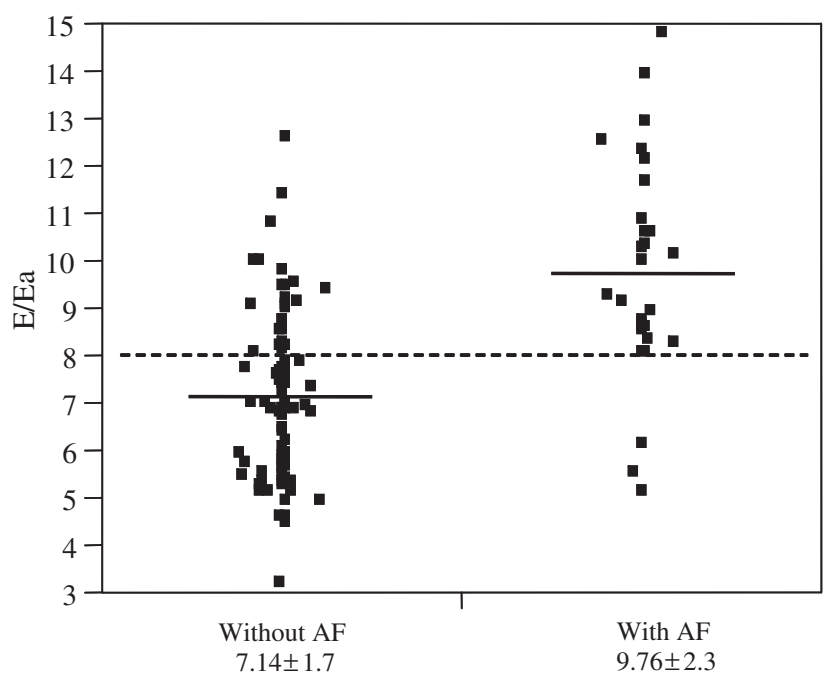

FIGURE 1. Preoperative early transmitral velocity/tissue Doppler mitral annular early diastolic velocity $(E / E a)$ ratios in patients with and without postoperative atrial fibrillation $(A F)$. Patients with postoperative AF had significantly higher $\mathrm{E} / \mathrm{Ea}$ values compared with values seen in those without $\mathrm{AF}(P<.0001)$.

postoperative $\mathrm{AF}$ had significantly impaired $\mathrm{FEV}_{1} / \mathrm{FVC}$ ratios and predicted postoperative $\mathrm{FEV}_{1}$ (as a percentage) compared with values seen in those without postoperative $\mathrm{AF}$ (Table 2). As for echocardiographic parameters, patients with postoperative AF had significantly lower Ea and higher E/Ea ratio values (Figure 1), as well as relatively impaired LV ejection fraction (Table 3), and therefore LV ejection fraction was important, although Ea and $\mathrm{E} / \mathrm{Ea}$ ratio values were more important for postoperative AF.

In receiver operating characteristic analysis the areas under the curve for age, $\mathrm{FEV}_{1} / \mathrm{FVC}$, and $\mathrm{E} / \mathrm{Ea}$ ratio to predict postoperative $\mathrm{AF}$ after pulmonary resection for lung cancer

TABLE 3. Preoperative echocardiographic variables*

\begin{tabular}{|c|c|c|c|}
\hline Variables & $\begin{array}{c}\text { Without AF } \\
\quad(\mathbf{n}=97)\end{array}$ & $\begin{array}{l}\text { With AF } \\
(n=29)\end{array}$ & $P$ value \\
\hline LVDd (mm) & $43.8 \pm 3.9$ & $43.2 \pm 3.5$ & .45 \\
\hline LVDs (mm) & $26.9 \pm 3.3$ & $27.9 \pm 3.7$ & .15 \\
\hline Ejection fraction $(\%)$ & $68.3 \pm 5.2$ & $65.5 \pm 5.4$ & .06 \\
\hline LV mass index $\left(\mathrm{g} / \mathrm{m}^{2}\right)$ & $110.8 \pm 25.4$ & $116.8 \pm 41.2$ & .27 \\
\hline PAP (mm Hg) & $33.6 \pm 5.5$ & $34.9 \pm 4.0$ & .34 \\
\hline E/A ratio & $0.87 \pm 0.3$ & $0.87 \pm 0.3$ & .83 \\
\hline $\operatorname{DcT}(\mathrm{ms})$ & $219 \pm 44$ & $220 \pm 49$ & .92 \\
\hline $\operatorname{AcT}(\mathrm{ms})$ & $134 \pm 20$ & $133 \pm 23$ & .86 \\
\hline $\mathrm{Ea}(\mathrm{cm} / \mathrm{s})$ & $8.46 \pm 2.0$ & $7.39 \pm 1.7$ & .008 \\
\hline $\mathrm{E} / \mathrm{Ea}$ & $7.14 \pm 1.7$ & $9.76 \pm 2.3$ & $<.0001$ \\
\hline
\end{tabular}

$A F$, Atrial fibrillation; $L V D d$, left ventricular end-diastolic diameter; $L V D s$, left ventricular end-systolic diameter; $L V$, left ventricular; $P A P$, pulmonary artery pressure; $E / A$, peak early diastolic mitral flow velocity to peak mitral flow velocity at atrial contraction; $D c T$, deceleration time of peak early diastolic mitral flow velocity; $A c T$, acceleration time of peak early diastolic mitral flow velocity; PAP, pulmonary artery pressure; $E a$, tissue Doppler mitral annular early diastolic velocity; $E / E a$, early transmitral velocity/tissue Doppler mitral annular early diastolic velocity. ${ }^{*}$ Values are shown as means \pm standard deviations. 
TABLE 4. Univariate and multivariate analyses of factors for prediction of postoperative AF

\begin{tabular}{|c|c|c|c|c|}
\hline \multirow[b]{2}{*}{ Variables } & \multicolumn{2}{|c|}{ Univariate analysis } & \multicolumn{2}{|c|}{ Multivariate analysis } \\
\hline & Relative risk $(95 \%$ CI $)$ & $P$ value & Relative risk $(95 \%$ CI $)$ & $P$ value \\
\hline Age & $1.094(1.031-1.162)$ & .003 & $1.058(0.983-1.138)$ & .13 \\
\hline $\mathrm{FEV}_{1} / \mathrm{FVC}$ & $0.947(0.903-0.994)$ & .03 & $1.010(0.946-1.078)$ & .77 \\
\hline ppo $\mathrm{FEV}_{1}, \%$ & $1.033(1.001-1.065)$ & .04 & $0.978(0.935-1.023)$ & .33 \\
\hline $\mathrm{E} / \mathrm{Ea}$ & $1.982(1.487-2.640)$ & .0001 & $1.810(1.356-2.417)$ & .0001 \\
\hline
\end{tabular}

$\overline{A F}$, Atrial fibrillation; $C I$, confidence interval; $F E V_{1}$, forced expiratory volume in 1 second; $F V C$, forced vital capacity; $p p o$, predicted postoperative; $E / E a$, early transmitral velocity/tissue Doppler mitral annular early diastolic velocity.

were $0.71,0.40$, and 0.83 , respectively ( $95 \%$ confidence interval, $0.61-0.82,0.28-0.52$, and $0.74-0.92$, respectively). An E/Ea ratio of 8 or greater had a sensitivity of $90 \%$, a specificity of $73 \%$, a positive predictive value of $51 \%$, and a negative predictive value of $96 \%$ for predicting postoperative AF. Univariate and multivariate analyses (Table 4) revealed that the preoperative $\mathrm{E} / \mathrm{Ea}$ ratio was the most significant predictor of postoperative AF.

\section{DISCUSSION}

The present results indicate that patients with postoperative $\mathrm{AF}$ have higher preoperative $\mathrm{E} / \mathrm{Ea}$ ratios compared with those seen in patients without postoperative $\mathrm{AF}$, and thus patients with LV diastolic dysfunction before surgical intervention might have an increased risk for postoperative AF. TDI is a promising and appropriate diagnostic tool to predict the development of postoperative AF after pulmonary resection for lung cancer.

The presence and severity of LV diastolic dysfunction are associated with an increased risk for first-time $\mathrm{AF}$ in patients with sinus rhythm. ${ }^{7,8}$ Older age, hypertension, female sex, diabetes and obesity, and LV hypertrophy have been reported as risk factors for diastolic heart failure. ${ }^{18}$ In addition, LV diastolic dysfunction has been frequently reported in patients with COPD. ${ }^{19,20}$ Some recent studies found that patients with right ventricular (RV) pressure or volume overload had a leftward shift of the ventricular septum toward the center of the LV cavity, ${ }^{21}$ resulting in a geometric distortion of the left ventricle. Leftward ventricular septal shift in patients with RV overload can explain LV filling abnormalities. Furthermore, Funk and colleagues ${ }^{22}$ reported that LV diastolic dysfunction was present in patients with COPD with normal pulmonary artery pressure. COPD with lung hyperinflation and distension leads to increased stiffness of the parietal pleura and thus of the walls of the cardiac fossa. ${ }^{23}$ Such a condition might contribute to LV diastolic dysfunction in patients with COPD independent of pulmonary hypertension, although that has not been established.

LV diastolic dysfunction in patients with lung cancer is caused by older age, essential hypertension, and COPD. Interestingly, patients with postoperative $\mathrm{AF}$ in the present study were significantly older $(P=.002)$ and had impaired $\mathrm{FEV}_{1} / \mathrm{FVC}$ ratios $(P=.03)$ compared with those without AF. In addition, hypertension was associated in $55 \%$ of our patients with postoperative $\mathrm{AF}$, whereas it was seen in $41 \%$ of those without AF.

Because of the absence of pseudonormalization, TDI has been proposed to be a valuable diagnostic tool for evaluating first-time LV diastolic dysfunction. ${ }^{11,14}$ Notably, E/Ea ratios were closely correlated with LV filling pressures. E is dependent on left atrial driving pressure, LV relaxation kinetics, and age, whereas Ea is mostly dependent on LV relaxation kinetics and age. Therefore for the $\mathrm{E} / \mathrm{Ea}$ ratio, the effects of LV relaxation kinetics and age are eliminated, and the value becomes a measure of left atrial driving pressure and LV filling pressure. Using the lateral mitral annulus for measurement, Nagueh and associates ${ }^{12}$ first demonstrated that $\mathrm{E} / \mathrm{E}$ a ratio was correlated well with pulmonary capillary wedge pressure. In addition, Ommen and coworkers ${ }^{13}$ used the mitral septal annulus and demonstrated that $\mathrm{E} / \mathrm{Ea}$ ratio had a reasonable correlation $(r=0.64$, $P<.001)$ with mean $\mathrm{LV}$ diastolic pressure in patients referred for left heart catheterization. Mitral E/Ea ratio measurement has since been used in multiple patient populations with cardiac disease to noninvasively estimate LV filling pressure and LV diastolic dysfunction. Recently, TDI was recommended as a first-line diagnostic approach for LV diastolic dysfunction by the European Society of Cardiology. ${ }^{14}$

Aç1 and colleagues ${ }^{24}$ reported that LV diastolic dysfunction assessed with TDI was not significantly associated with postoperative $\mathrm{AF}$ after coronary artery bypass grafting. The mechanisms of postoperative AF might be different between patients undergoing pulmonary resection surgery and those undergoing cardiac surgery, which could have various factors, such as extent of valvular heart disease, myocardial ischemia, and cardiac mechanical injury. However, in our patient population RV overload caused by pulmonary resection was considered to be measured without other complicating factors. However, an $\mathrm{E} / \mathrm{Ea}$ ratio had no higher negative predictive value, and therefore we could not predict clearly the development of postoperative $\mathrm{AF}$ by using the $\mathrm{E} / \mathrm{Ea}$ ratio only.

To the best of our knowledge, this is the first study to evaluate LV diastolic function with TDI as a possible predictor for the development of postoperative $\mathrm{AF}$ in patients undergoing pulmonary resection for lung cancer. Our study provides a new prospective in terms of prophylactic strategies for postoperative AF. We can speculate that the patients with preoperative higher $\mathrm{E} / \mathrm{Ea}$ ratios might be able to prevent 
postoperative $\mathrm{AF}$ with $\beta$-blockers or statins before surgical intervention. In Japan the cost of echocardiographic analysis is only 8,800 yen (about 95 dollars), and the recording of TDI during an echocardiographic study does not require an additional fee. Thus preoperative TDI recording is likely cost-effective for patients who have risk factors of LV systolic and diastolic dysfunction.

\section{Study Limitations}

This study was a single-institution clinical study, which restricted our ability to generalize the results. In addition, the number of patients in the study cohort was relatively small, and thus additional investigations are necessary to define the utility of TDI for predicting postoperative AF in patients undergoing pulmonary resection for lung cancer. Finally, echocardiographic examinations were not performed after the operation, and therefore there are no data regarding the presence of RV overload or LV diastolic dysfunction after surgical intervention. Nevertheless, the present method can be applied to assess the development of postoperative $\mathrm{AF}$ in all non-cardiac surgery patients.

\section{CONCLUSIONS}

LV diastolic dysfunction before surgical intervention revealed by TDI might be associated with the development of postoperative $\mathrm{AF}$ after pulmonary resection for lung cancer. Additional studies to establish the significance of TDI as a tool to predict postoperative AF might contribute to improvements in lung cancer treatments.

\section{References}

1. Cardinale D, Martinoni A, Cipolla CM, Civelli M, Lamantia G, Fiorentini C, et al. Atrial fibrillation after operation for lung cancer: clinical and prognostic significance. Ann Thorac Surg. 1999;68:1827-31.

2. Roselli EE, Murthy SC, Rice TW, Houghtaling PL, Pierce CD, Karchmer DP, et al. Atrial fibrillation complicating lung cancer resection. J Thorac Cardiovasc Surg. 2005; 130:438-44

3. Matsubara Y, Takeda S, Mashimo T. Risk stratification for lung cancer surgery. Chest. 2005;128:3519-25.

4. Sekine Y, Kesler K, Behnia M, Brooks-Brunn J, Sekine E, Brown JW. COPD may increase the incidence of refractory supraventricular arrhythmias following pulmonary resection for non-small cell lung cancer. Chest. 2001;120:1783-90.

5. Amar D, Roistacher N, Burt M, Reinsel RA, Ginsberg RJ, Wilson RS. Clinical and echocardiographic correlates of symptomatic tachydysrhythmias after noncardiac thoracic surgery. Chest. 1995;108:349-54.

6. Vaporciyan AA, Correa AM, Rice DC, Roth JA, Smythe WR, Swisher SG, et al. Risk factors associated with atrial fibrillation after noncardiac thoracic surgery. J Thorac Cardiovasc Surg. 2004;127:779-86.
7. Al-Omari MA, Finstuen J, Appleton CP, Barnes ME, Tsang TS. Echocardiographic assessment of left ventricular diastolic function and filling pressure in atrial fibrillation. Am J Cardiol. 2008;101:1759-65.

8. Tsang TS, Gersh BJ, Appleton CP, Tajik AJ, Barnes ME, Bailey KR, et al. Left ventricular diastolic dysfunction as a predictor of the first diagnosed nonvalvular atrial fibrillation in 840 elderly men and woman. J Am Coll Cardiol. 2002;40: 1636-44.

9. Yamamoto K, Redfield MM, Nishimura RA. Analysis of left ventricular diastolic function. Heart. 1996;75(suppl 2):27-35.

10. Yamamoto K, Nishimura RA, Chaliki HP, Appleton CP, Holmes DR Jr, Redfield MM. Determination of left ventricular filling pressure by Doppler echocardiography in patients with coronary artery disease: critical role of left ventricular systolic function. J Am Coll Cardiol. 1997;30:1819-26.

11. Kasner M, Westermann D, Steendijk P, Gaub R, Wilkenshoff U, Weitmann K, et al. Utility of Doppler echocardiography and tissue Doppler imaging in the estimation of diastolic function in heart failure with normal ejection fraction: a comparative Doppler-conductance catheterization study. Circulation. 2007;116: 637-47.

12. Nagueh SF, Middleton KJ, Kopelen HA, Zoghbi WA, Quinones MA. Doppler tissue imaging: a noninvasive technique for evaluation of left ventricular relaxation and estimation of filling pressures. J Am Coll Cardiol. 1997;30:1527-33.

13. Ommen SR, Nishimura RA, Appleton CP, Miller FA, Oh JK, Redfield MM, et al. Clinical utility of Doppler echocardiography and tissue Doppler imaging in the estimation of left ventricular filling pressures: a comparative simultaneous Doppler-catheterization study. Circulation. 2000;102:1788-94.

14. Paulus WJ, Tschöpe C, Sanderson JE, Rusconi C, Flachskampf FA, Rademakers FE, et al. How to diagnose diastolic heart failure: a consensus statement on the diagnosis of heart failure with normal left ventricular ejection fraction by the Heart Failure and Echocardiography Associations of the European Society of Cardiology. Eur Heart J. 2007;28:2539-50.

15. Nakahara K, Monden Y, Ohno K, Miyoshi S, Maeda H, Kawashima Y. A method for predicting postoperative lung function and its relation to postoperative complications in patients with lung cancer. Ann Thorac Surg. 1985;39:260-5.

16. Devereux RB, Reichek N. Echocardiographic determination of left ventricular mass in man. Anatomic validation of the method. Circulation. 1977;55:613-8.

17. Currie PJ, Seward JB, Chan KL, Fyfe DA, Hagler DJ, Mair DD, et al. Continuous wave Doppler determination of right ventricular pressure: a simultaneous Doppler-catheterization study in 127 patients. J Am Coll Cardiol. 1985;6:750-6.

18. Almuntaser I, Brown A, Murphy R, Crean P, King G, Mahmud A, et al. Comparison of echocardiographic measures of left ventricular diastolic function in early hypertension. Am J Cardiol. 2007; 100:1771-5.

19. Tutar E, Kaya A, Güleç S, Ertaş F, Erol C, Ozdemir O, et al. Echocardiographic evaluation of left ventricular diastolic function in chronic cor pulmonale. Am J Cardiol. 1999;83:1414-7.

20. Boussuges A, Pinet C, Molenat F, Burnet H, Ambrosi P, Badier M, et al. Left atrial and ventricular filling in chronic obstructive pulmonary disease: an echocardiographic and Doppler study. Am J Respir Crit Care Med. 2000;162:670-5.

21. Louie EK, Lin SS, Reynertson SI, Brundage BH, Levitsky S, Rich S. Pressure and volume loading of the right ventricle have opposite effects on left ventricular ejection fraction. Circulation. 1995;92:819-24.

22. Funk GC, Lang I, Schenk P, Valipour A, Hartl S, Burghuber OC. Left ventricular diastolic dysfunction in patients with COPD in the presence and absence of elevated pulmonary arterial pressure. Chest. 2008;133:1354-9.

23. Butler J. The heart is in good hands. Circulation. 1983;67:1163-8.

24. Açıl T, Cölkesen Y, Türköz R, Sezgin AT, Baltali M, Gülcan O, et al. Value of preoperative echocardiography in the prediction of postoperative atrial fibrillation following isolated coronary artery bypass grafting. Am J Cardiol. 2007;100: 1383-6. 